Article

\title{
Trend Analysis of Hydroclimatic Variables in the Kamo River Basin, Japan
}

\author{
Maochuan Hu ${ }^{1, * \mathbb{C}}$, Takahiro Sayama ${ }^{1} \mathbb{D}$, Sophal TRY ${ }^{2,3}$, Kaoru Takara $^{4}$ and Kenji Tanaka ${ }^{1}$ \\ 1 Disaster Prevention Research Institute, Kyoto University, Uji 611-0011, Japan \\ 2 Graduate School of Engineering, Kyoto University, Kyoto 615-8510, Japan \\ 3 Faculty of Hydrology and Water Resources Engineering, Institute of Technology of Cambodia, \\ Phnom Penh 12150, Cambodia \\ 4 Graduate School of Advanced Integrated Studies in Human Survivability, Kyoto University, \\ Kyoto 606-8306, Japan \\ * Correspondence: maochuanhu@gmail.com
}

Received: 19 August 2019; Accepted: 22 August 2019; Published: 27 August 2019

check for updates

\begin{abstract}
Understanding long-term trends in hydrological and climatic variables is of high significance for sustainable water resource management. This study focuses on the annual and seasonal trends in precipitation, temperature, potential evapotranspiration, and river discharge over the Kamo River basin from the hydrological years 1962 to 2017. Homogeneity was examined by Levene's test. The Mann-Kendall and a modified Mann-Kendall test as well as Sen's slope estimator were used to analyze significant trends $(p<0.05)$ in a time series with and without serial correlation and their magnitudes. The results indicate that potential evapotranspiration calculated by the Penman-Monteith equation was highly related to temperature, and significantly increased in the annual and summer series. Annual river discharge significantly decreased by $0.09 \mathrm{~m}^{3} / \mathrm{s}$. No significant trend was found at the seasonal scale. Annual, autumn, and winter precipitation at Kumogahata station significantly increased, while no significant trend was found at Kyoto station. Precipitation was least affected by the modified Mann-Kendall test. Other variables were relatively highly autocorrelated. The modified Mann-Kendall test with a full autocorrelation structure improved the accuracy of trend analysis. Furthermore, this study provides information for decision makers to take proactive measures for sustainable water management.
\end{abstract}

Keywords: precipitation; temperature; potential evapotranspiration; river discharge; Mann-Kendall test

\section{Introduction}

In recent decades, climate change has been profoundly influencing the hydroclimatic system at various spatial scales [1], which caused many effects (e.g., flood, drought, and heat) and consequently impacted the survival and sustainability of humanity [2-4]. As a subject of extensive climate change studies, trend analysis in hydroclimatic time-series has received growing attention over the world in recent years [5]. Hydroclimatic variables are important indicators of climate change, which play a key role in the hydrological cycle and natural disasters [6-8]. The variations of hydroclimatic variables are useful information for sustainable water management and decision makers.

Numerous studies worldwide have assessed spatiotemporal trends in hydroclimatic variables [9-11]. There was a significant decreasing trend of annual river discharge in a sub-basin of the Lake Baikal basin in Mongolia from 1979 to 2016 [12]. No significant long-term trends in precipitation were found in India nationwide [13]. In the contiguous U.S., a significant downward trend in temperature in the southeast and upward trend elsewhere were identified from 1898 to 2008 [14]. In Japan, temperature significantly increased from 1900 to 1996 [15]. Hydroclimatic variations always 
vary among geographic locations [16]. Oguchi and Fujibe [17] concluded that features of precipitation changes in Japan have regional differences. Understanding long-term trends in hydroclimatic variables at each catchment is very important to the national and local water management. Furthermore, trend analysis of hydroclimatic variables in each basin using local historical data over the world contributes to better understanding of the global climate change.

Most of trend studies have used the original Mann-Kendall (MK) test, assuming spatiotemporal independence in the data [18,19]. The presence of serial correlation in data has great effects on the significance of trends [20]. In Japan, there is a paucity of literature on the effects of serial correlation during trend analysis [21]. In this study, the original MK and a modified Mann-Kendall (MMK) test considering full autocorrelation structure were used to reveal the effects of autocorrelations in trend analysis in a Japanese basin.

As one of the most famous historical rivers and an important freshwater ecosystem in Japan, modern water management in the Kamo River basin lasts for hundreds of years. What are the variations in hydroclimatic variables? Are the changes caused by human activities or climate change? Few studies have examined the trends of hydroclimatic variables in the basin, which need to be characterized to address these questions. Therefore, this study analyzed the trends in precipitation, temperature (in terms of maximum, minimum, and mean values), potential evapotranspiration, and river discharge in the Kamo River basin at both annual and seasonal scales using the MK and MMK tests. While potential evapotranspiration was calculated by using the Penman-Monteith equation, others were obtained from observed records. The objectives of this study are: (1) to identify the trends in hydroclimatic variables at a 5\% level; (2) to quantify the magnitudes of trends; and (3) to estimate the effects of serial correlation on trends.

\section{Methodology}

\subsection{Study Area and Data Source}

The study area is the Kamo River basin $\left(180 \mathrm{~km}^{2}\right.$, discharge gauge at Fukakusa; Figure 1), ranging from 135.7 E to 135.86 E and 34.97 N to 35.18 N. A tributary of the Yodo River, the Kamo River, flows through Kyoto city, which is the historical capital of Japan. The downtown of Kyoto and many historic sites are distributed at waterfronts of the Kamo River. The basin has an elevation ranging from $17 \mathrm{~m}$ to $888 \mathrm{~m}$, with $70 \%$ of forest. There are two meteorological stations with good quality long-term data (Figure 1). One is out of the basin with an elevation of $41 \mathrm{~m}$ (Kyoto station). The other is within the basin with an elevation of $250 \mathrm{~m}$ (Kumogahata station). 


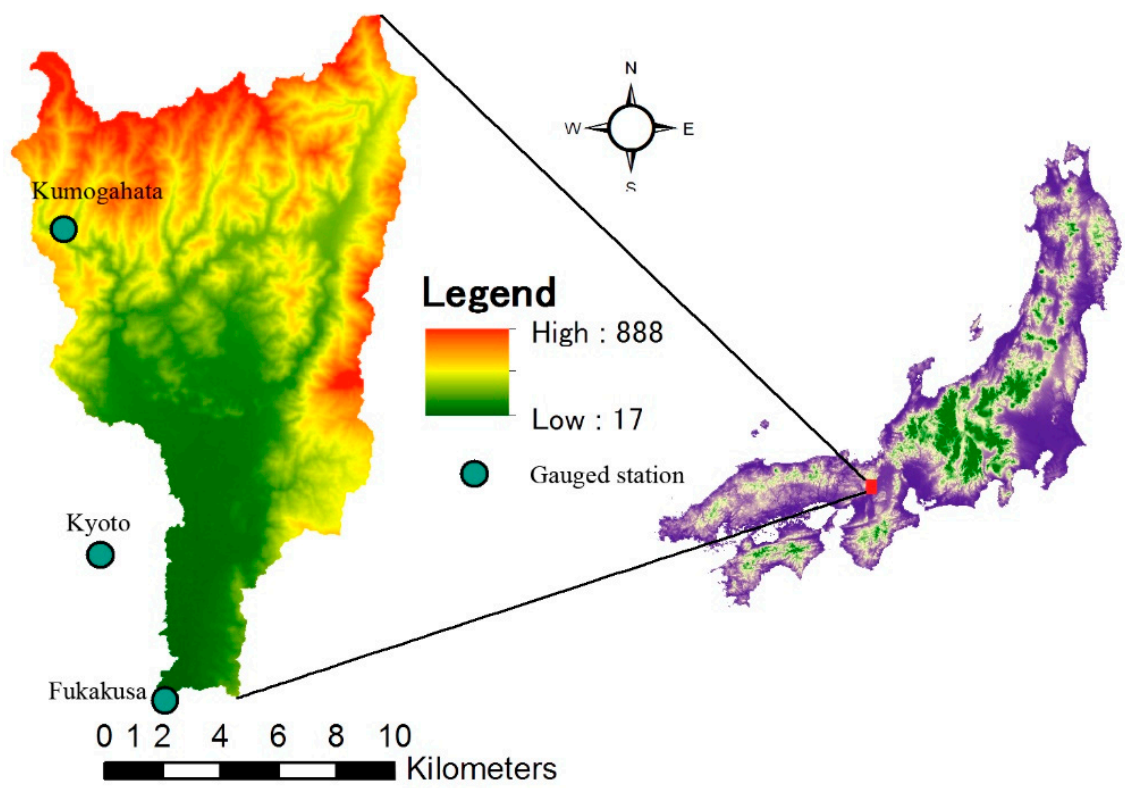

Figure 1. Study area and information of gauged stations.

In this study, hydrological year (from December to the following November) was used for statistical analyses. Meteorological data including precipitation, temperature (mean, maximum and minimum), wind speed, sunshine duration, relative humidity, and vapor pressure at Kyoto station from the hydrological year 1962 to 2017 (from December 1961 to November 2017, hereafter all months and years were hydrological by default) were obtained from Japan Meteorological Agency. Precipitation at Kumogahata and river discharge at Fukakusa station from 1962 to 2017 were provided by Ministry of Land, Infrastructure, Transport, and Tourism. If continuous missing data in a season or a year were more than 10 or 20 days, respectively, then the seasonal or year value was processed as missing.

\subsection{Homogeneity Test}

A homogeneity assessment of hydroclimatic data before test detection is important, because observed long-term data series are easily affected by external factors such as displacement of station location, application of certain practice, environment change, and so on. It is necessary to detect and adjust the non-homogeneities. Metadata inspection and statistical tests are commonly used for homogeneity adjustment [22,23]. The popular statistical methods include standard normal homogeneity test, two-phase regression, multiple linear regression, t-test, Levene's test, and rank order change point test (non-parametric test) [22].

In this study, the homogeneity tests were conducted in the software of SPSS using Levene's test method [24]. The family of Levene's test has three types. The first is an original or traditional Levene's test using group means, the second is named the Brown-Forsythe test using group medians, and the last one is called the non-parametric Levene's test, which performs a traditional Levene's test on pooled ranked values. Here, the original and the last types were used. We assumed that a potential changing point could be any date of the monitored data period, and we broke the data series (size $N$ ) into $k$ subgroups, where $N_{i}$ is the sample size of the $i^{t h}$ subgroup. The null hypothesis $H_{0}$ is that there are no significant differences between each two groups at the confidence level of $95 \%$. The original Levene's test statistic $L$ is defined as:

$$
L=\frac{(N-k)}{(k-1)} \frac{\sum_{i=1}^{k} N_{i}\left(\bar{O}_{i}-\bar{O}\right)^{2}}{\sum_{i=1}^{k} \sum_{j=1}^{N_{i}}\left(O_{i j}-\bar{O}_{i}\right)^{2}}
$$


In this equation, $\bar{O}_{i}$ is the mean of $i^{t h}$ group, and $\bar{O}$ is the overall mean of the $O_{i j}$. $O_{i j}$ is calculated using the following equation:

$$
O_{i j}=\left|y_{i j}-\bar{y}_{i}\right|
$$

where $y_{i j}$ is the value of the measured variable for the $j^{\text {th }}$ case from the $i^{\text {th }}$ group; $\bar{y}_{i}$ is the mean of the $i^{\text {th }}$ group. If $W$ is more than the value of $F(0.05, k-1, N-k)$, the Levene's test rejects $H_{0}$. There are heterogeneities in the data series. $F(0.05, k-1, N-k)$ is the upper critical value of the $F$-distribution at the significance level of 0.05 with $k-1$ and $N-k$ degrees of freedom.

\subsection{Potential Evapotranspiration}

The potential evapotranspiration was calculated based on the equation of Penman-Monteith FAO 56 [25], which is the most commonly used method for potential evapotranspiration estimation. It could be defined as:

$$
E T_{0}=\frac{\left[0.408 S\left(R_{n}-G\right)+\frac{900 r W\left(e_{s}-e_{a}\right)}{T+273}\right]}{[U+r(1+0.24 W)]}
$$

where $E T_{0}$ is the potential evapotranspiration (mm); $U$ is the slope vapor pressure curve $\left(\mathrm{kPa}^{\circ} \mathrm{C}^{-1}\right)$; $R_{n}$ is net radiation $\left(\mathrm{MJm}^{-2} \mathrm{day}^{-1}\right) ; G$ is the soil heat flux density $\left(\mathrm{MJm}^{-2} \mathrm{day}^{-1}\right) ; r$ is the psychrometric constant $\left(\mathrm{kPa}^{\circ} \mathrm{C}^{-1}\right) ; W$ is the wind speed $\left(\mathrm{ms}^{-1}\right) ; e_{s}$ and $e_{a}$ are the saturation and actual vapor pressure, respectively $(\mathrm{kPa})$; and $\mathrm{T}$ is the daily air temperature $\left({ }^{\circ} \mathrm{C}\right)$.

\subsection{Trend Analysis}

\subsubsection{Mann-Kendall Test}

The MK test $[26,27]$ has been widely used in hydroclimatic analyses during the past decades $[9,28]$ due to the low requirements of data quality and distribution [10]. The MK test assumes that observations are independent and random. There is no serial correlation in observations. The significance test $Z$ and test statistic $S$ are described as:

$$
\begin{gathered}
S=\sum_{h=1}^{n-1} \sum_{t=h+1}^{n} F\left(y_{t}-y_{h}\right) \\
F(\varnothing)=\left\{\begin{array}{cc}
1 & \text { if } \varnothing>0 \\
0 & \text { if } \varnothing=0 \\
-1 & \text { if } \varnothing<0
\end{array}\right. \\
\operatorname{Var}(S)=\frac{\left[n(n-1)(2 n+5)-\sum_{d} d(d-1)(2 d+5)\right]}{18} \\
Z=\left\{\begin{array}{cc}
\frac{S-1}{\sqrt{\operatorname{Var}(S)}} & \text { if } S>0 \\
0 & \text { if } S=0 \\
\frac{S+1}{\sqrt{\operatorname{Var}(S)}} & \text { if } S<0
\end{array}\right.
\end{gathered}
$$

where $y$ is the hydroclimatic variable and $\varnothing=y_{t}-y_{h}$; and $d$ is the extent of any given tie. The statistical significance level $p=0.05$ is used in this study. Thus, if $Z$ is no less than 1.96 , there is a significant increasing trend. Whereas, if $Z$ is no greater than -1.96 , there is a significant decreasing trend.

\subsubsection{Modified Mann-Kendall Test}

As mentioned above, the MK test neglects the effects of serial correlation, which are important for statistical analysis [20,29]. Therefore, the MMK test considering a full autocorrelation structure [30] 
is also used to analyze the monotonic trends in hydrological variables. Compared with the MK test, the MMK test modified Equation (7) by using a function $V(S)$ to replace $\operatorname{Var}(S)$ :

$$
\begin{gathered}
V(S)=\operatorname{Var}(S) \times\left(1+\frac{2}{n(n-1)(n-2)} \sum_{h=1}^{n-1}(n-h)(n-h-1)(n-h-2) R_{h}\right) \\
R_{h}=\frac{n \sum_{c=1}^{n-h}\left(y_{c}-\bar{y}\right)\left(y_{c+h}-\bar{y}\right)}{(n-h) \sum_{c=1}^{n}\left(y_{c}-\bar{y}\right)^{2}}
\end{gathered}
$$

\subsubsection{Sen's Slope Estimator}

The non-parametric Sen's Slope procedure, developed by Sen [31], is used to estimate the changes over a period in hydrological variables. The magnitude $Q$ is computed using the following equation:

$$
Q=\text { median }\left[\frac{\left(m_{b}-m_{a}\right)}{(b-a)}\right] \text { for all } a<b
$$

where $m_{b}$ and $m_{a}$ are the values at times $b$ and $a(b>a)$, respectively.

\section{Results}

\subsection{Homogeneity Test}

The results of homogeneity adjustment in meteorological variables show that there were no non-homogeneities in the data at annual and seasonal scales. For streamflow, each test found heterogeneities in the data from 1962 to 2017. The observed data from 1978 to 1987 were outliers compared with the data in other periods (Figure 2). Excluding the data from 1978 to 1987, the results of the homogeneity test on the remaining data show that there were no heterogeneities at annual and seasonal scales. Table 1 shows the results of the homogeneity test on all the variables at the annual scale.

Table 1. Results of homogeneity test on hydroclimatic data at the annual scale.

\begin{tabular}{cccc}
\hline \multirow{2}{*}{ Data Type } & \multicolumn{2}{c}{ Homogeneity } & \multirow{2}{*}{ Period } \\
\cline { 2 - 3 } & Levene's Test & Non-Parametric Levene's Test & \\
\hline Precipitation at Kyoto station & Yes & Yes & $1962-2017$ \\
Precipitation at Kumogahata station & Yes & Yes & $1962-2017$ \\
Mean temperature & Yes & Yes & $1962-2017$ \\
Maximum temperature & Yes & Yes & $1962-2017$ \\
Minimum temperature & Yes & Yes & $1962-2017$ \\
Potential evapotranspiration & Yes & Yes & $1962-2017$ \\
\hline River discharge & No & No & $1962-2017$ \\
\hline
\end{tabular}

\subsection{Variations of Precipitation}

The annual precipitation at Kumogahata station notably increased at the 5\% level from 1962 to 2017 (Table 2). The value of slope reached 5.25 (Figure 2). However, no significant trend was found in annual precipitation at Kyoto station. Figure 3 shows the annual anomalies of precipitation relative to the mean value from 1981 to 2010 at both analyzed stations. Positive values indicate that the precipitation was larger than the means from 1981 to 2010, while negative values indicate the opposite. There was a relatively wet period from 1965 to 1972 at Kyoto station, while there was simultaneously a relatively dry period at Kumogahata station. The fluctuations at the two stations were strong from 1974 to 2017.

At the seasonal scale, winter precipitation (from January to March) significantly increased at both stations with MK test (Table 3). The winter data at Kyoto station had no significant trend at 5\% 
when the full autocorrelation structure (MMK) was considered. No significant trends were found in spring (from April to June) and summer (from July to September) precipitation at both stations. Autumn precipitation (from October to December) significantly increased at Kumogahata station.

Table 2. Results of trend analysis in annual hydroclimatic variables from 1962 to 2017.

\begin{tabular}{|c|c|c|c|c|c|c|c|c|}
\hline \multirow{2}{*}{\multicolumn{2}{|c|}{ Data Type }} & \multicolumn{2}{|c|}{$\mathbf{Z}$} & \multirow{2}{*}{ Slope } & \multirow{2}{*}{ Data Type } & \multicolumn{2}{|c|}{$\mathbf{Z}$} & \multirow{2}{*}{ Slope } \\
\hline & & MK & MMK & & & MK & MMK & \\
\hline \multirow{2}{*}{ Precipitation } & Kyoto & -0.40 & -0.62 & -0.94 & Maximum temperature & 3.95 & 1.79 & 0.02 \\
\hline & Kumogahata & 2.08 & 2.10 & 5.25 & Minimum temperature & 6.27 & 2.22 & 0.03 \\
\hline \multicolumn{2}{|c|}{ River discharge } & -3.88 & -1.98 & -0.09 & Mean temperature & 5.61 & 2.14 & 0.03 \\
\hline \multicolumn{2}{|c|}{ Potential evapotranspiration } & 4.62 & 1.99 & 1.23 & & & & \\
\hline
\end{tabular}

Table 3. Results of trend analysis in seasonal hydroclimatic variables from 1962 to 2017.

\begin{tabular}{|c|c|c|c|c|c|c|c|c|c|c|c|c|}
\hline \multirow{3}{*}{ Data Type } & \multicolumn{3}{|c|}{ Spring } & \multicolumn{3}{|c|}{ Summer } & \multicolumn{3}{|c|}{ Autumn } & \multicolumn{3}{|c|}{ Winter } \\
\hline & \multicolumn{2}{|c|}{$\mathbf{Z}$} & \multirow{2}{*}{ Slope } & \multicolumn{2}{|c|}{$\mathbf{Z}$} & \multirow{2}{*}{ Slope } & \multicolumn{2}{|c|}{$\mathbf{Z}$} & \multirow{2}{*}{ Slope } & \multicolumn{2}{|c|}{$\mathbf{Z}$} & \multirow{2}{*}{ Slope } \\
\hline & MK & MMK & & MK & MMK & & MK & MMK & & MK & MMK & \\
\hline Precipitation at Kyoto station & -1.60 & -1.95 & -1.50 & -1.6 & -1.91 & -2.46 & 0.96 & 1.57 & 1.08 & 2.06 & 1.76 & 0.96 \\
\hline Precipitation at Kumogahata station & -0.07 & -0.17 & -0.15 & 0.41 & 0.80 & 0.63 & 2.67 & 2.15 & 3.47 & 3.87 & 1.98 & 2.85 \\
\hline River discharge & -3.58 & -1.83 & -0.10 & -3.02 & -1.74 & -0.14 & -1.97 & -1.26 & -0.06 & -2.37 & -1.34 & -0.05 \\
\hline Potential evapotranspiration & 3.17 & 1.68 & 0.32 & 3.20 & 2.21 & 0.39 & 4.77 & 1.91 & 0.38 & 4.08 & 1.88 & 0.14 \\
\hline Maximum temperature & 2.86 & 1.77 & 0.02 & 3.27 & 1.98 & 0.02 & 3.76 & 1.84 & 0.03 & 1.28 & 1.37 & 0.01 \\
\hline Minimum temperature & 3.82 & 1.99 & 0.03 & 5.45 & 2.14 & 0.03 & 5.44 & 2.04 & 0.05 & 3.61 & 1.83 & 0.03 \\
\hline Mean temperature & 3.49 & 1.96 & 0.02 & 4.26 & 2.06 & 0.03 & 4.89 & 1.98 & 0.04 & 2.48 & 1.73 & 0.02 \\
\hline
\end{tabular}

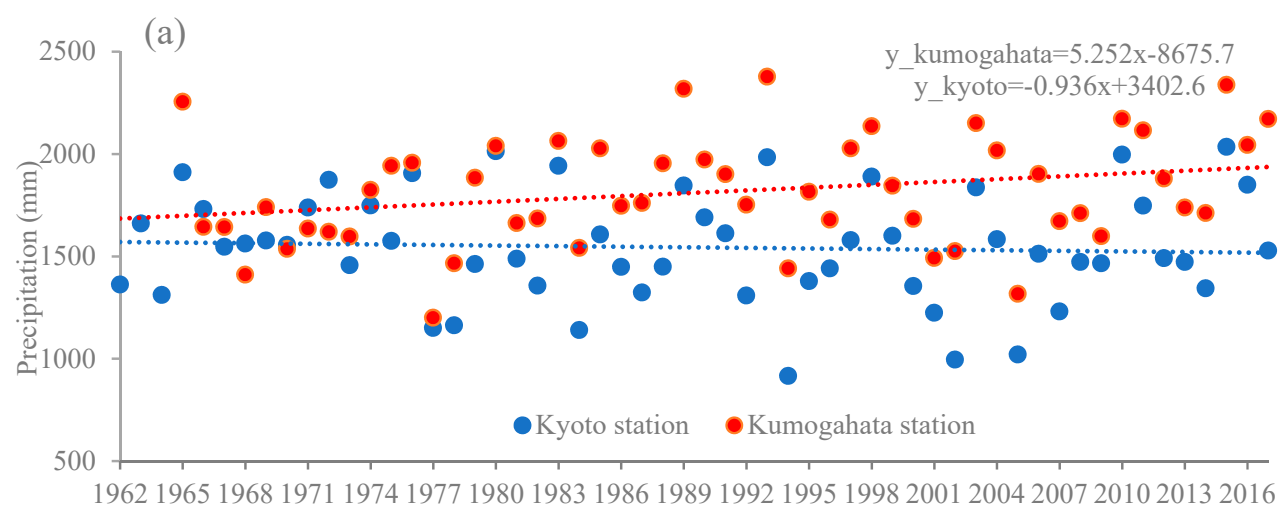

(b)

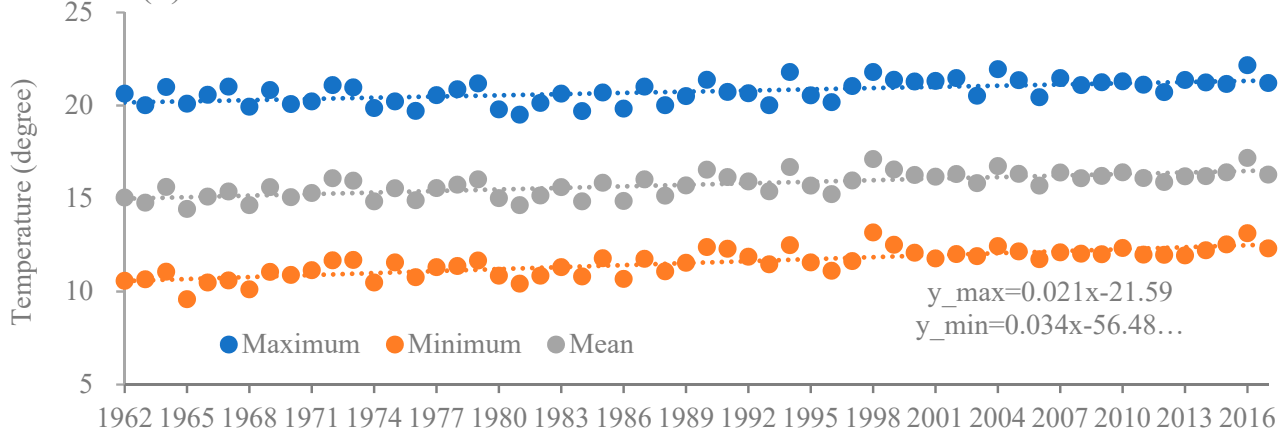

Figure 2. Cont. 
(c)

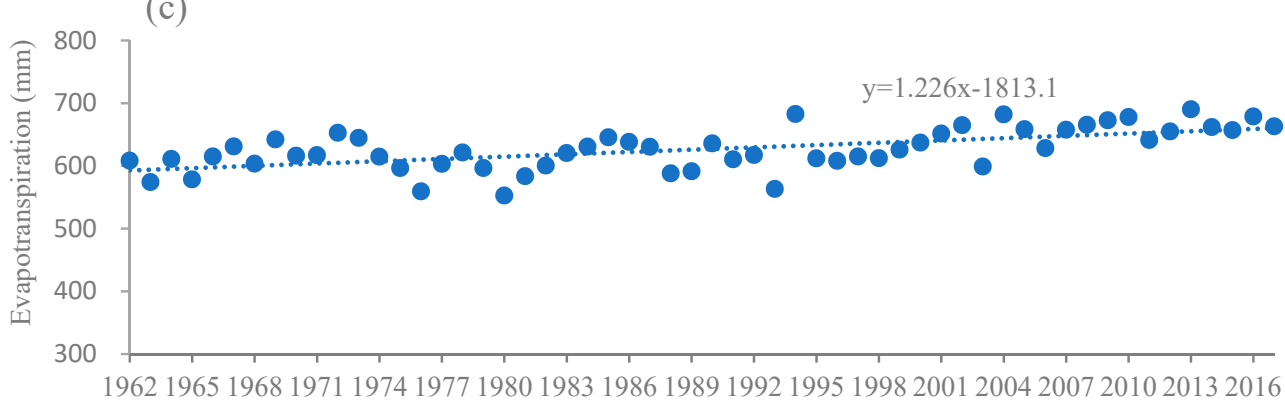

(d)

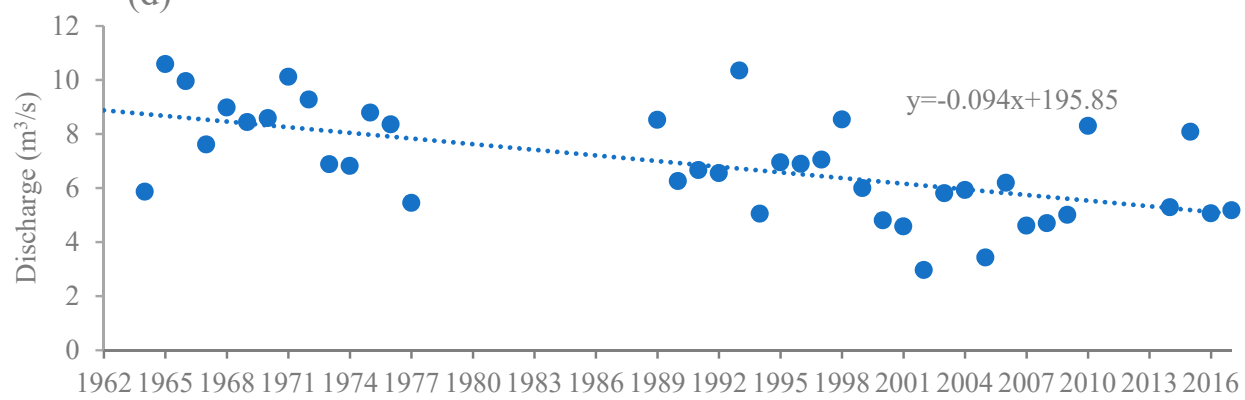

Figure 2. Annual time series of (a) annual precipitation; (b) annual temperature; (c) annual potential evapotranspiration; and (d) annual river discharge from 1962 to 2017 in the Kamo River basin.
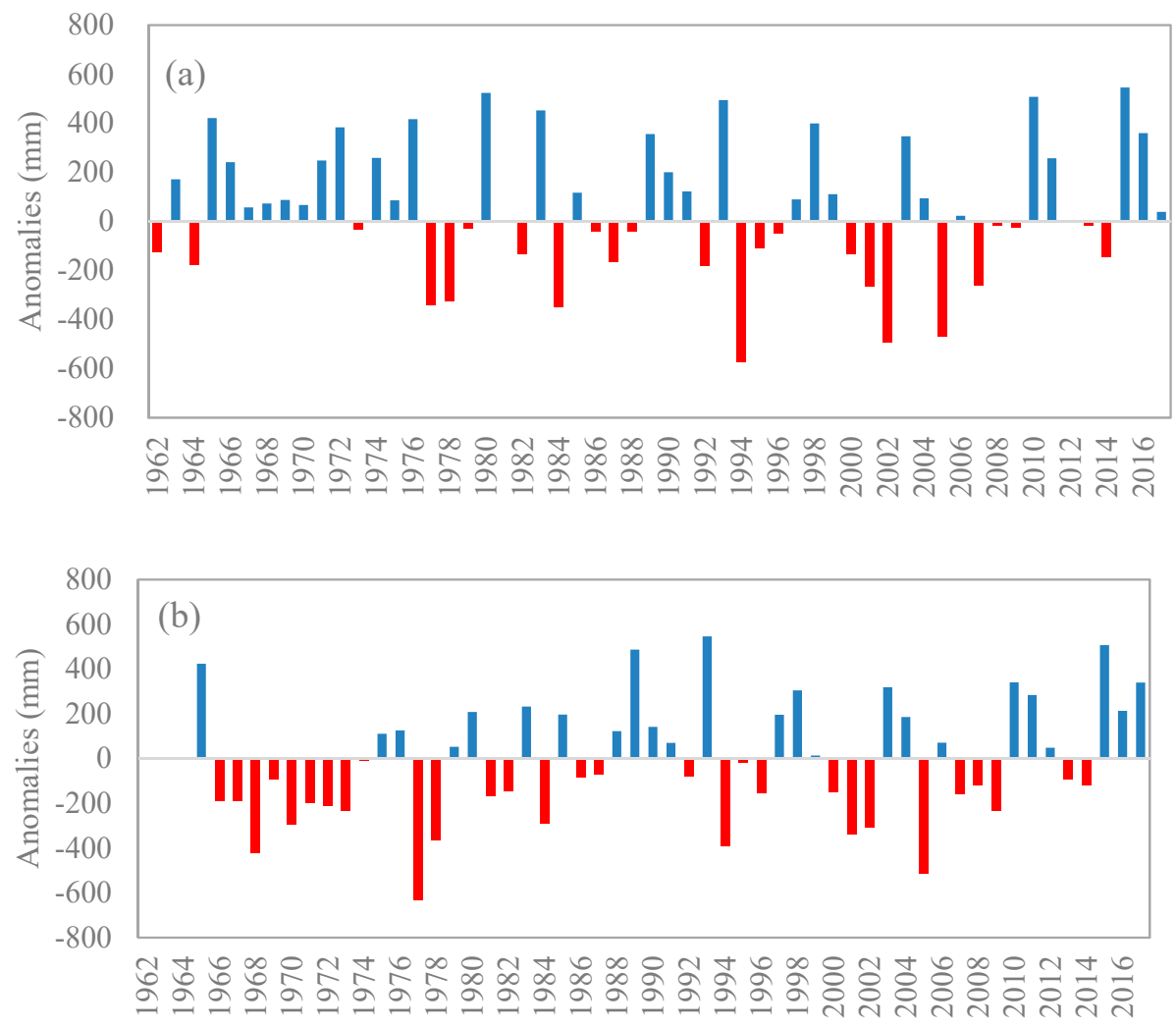

Figure 3. Annual time series of precipitation anomalies relative to the average value from 1981 to 2010 at (a) Kyoto station and (b) Kumogahata station in the Kamo River basin. 


\subsection{Variations of Temperature}

The results of trend identification in annual temperature variables are shown in Table 2. The minimum temperature and mean temperature had noticeable increasing trends from 1962 to 2017 (Figure 2). The maximum temperature, which notably rose with the MK test, did not show significant trend when the full autocorrelation structure (MMK) was considered in the trend analysis. Seasonal maximum, minimum, and mean temperatures also increased from 1962 to 2017, but there were no statistical significant at the $5 \%$ level in some seasons. Similarly, the number of seasonal variables with significant trends reduced when the full autocorrelation structure (MMK) was considered. The values of Sen's slope indicate that the increase of temperature in autumn was the highest. The magnitude of trend in minimum temperature was higher than the one in maximum temperature.

\subsection{Variations of Potential Evapotranspiration}

It was found that the annual potential evapotranspiration significantly increased by $1.23 \mathrm{~mm}$ per year from 1962 to 2017 (Table 2). Seasonal potential evapotranspiration also significantly increased in all seasons by the MK test. Only summer potential evapotranspiration rose notably when the full autocorrelation structure (MMK) was considered at the 5\% level. The magnitude of trend in summer was the highest, followed by autumn, spring, and winter.

\subsection{Variations of River Discharge}

According to the results of the homogeneity test, the decreasing trend was found for river discharge from 1962 to 2017 after discarding the outliers of 1978-1987. Annual river discharge significantly decreased by $0.09 \mathrm{~m}^{3} / \mathrm{s}$ per year (Figure 2). Also, a notable decrease was found in all seasons at the level of $5 \%$ by MK test. However, no significant trend was found when the full autocorrelation structure (MMK) was considered.

\section{Discussion}

\subsection{Implication of Trend Analysis}

A significant increase in annual precipitation at Kumogahata station was found, and the fluctuation of anomalies became more frequent and intense since the 1970s at both analyzed stations. Thus, the risk of alternate drought and flood probably increased, although there was no significant trend in annual precipitation at Kyoto station. In addition, the characteristics of changes in precipitation were different at the two gauged stations. For instance, the data at Kyoto station indicate that there was relatively wetter period from 1964 to 1972, while the data indicate the opposite at Kumogahata station. The probable reason for the discrepancy might be the differences in the terrains where the stations are located, as water vapor fluxes on different terrains are different [32]. Mountain terrain comprises about 70\% of the surface in the Kamo River basin; in addition, Kumogahata station is in the mountains at an elevation of $250 \mathrm{~m}$, while Kyoto station is located on a plain with the elevation of $41 \mathrm{~m}$. Moreover, the weakening of the winter monsoon over Japan, which can be regarded as the distribution of winter precipitation over Japan, was reported by some studies [33,34]. However, an increase in winter precipitation was found in the Kamo River basin. Therefore, precipitation changes are less regular in different regions. Upward trends were observed in temperature and potential evapotranspiration, which are consistent with the findings of some studies in Japan [15,35].

\subsection{Relations of Hydroclimatic Variables}

Annual river discharge has significantly decreased by discarding the outliers. The variations of streamflow were different from the variations of precipitation. In addition, no decreasing trend was found on the annual values of precipitation minus potential evapotranspiration (P-E) from 1962 to 2017 (note: the basin average precipitation was calculated by Thiessen polygon interpolation). 
Meanwhile, the study area is a highly managed river basin. The urban drainage area increased about 380\% from 1962 to the present [36], and the water in urban pipes flow to the downstream of the study area. The decrease in river discharge is very likely to be caused by human activities. Potential evapotranspiration was highly related with temperature. It rose with the increase of temperature. However, the magnitudes of trends among them were inconsistent. Maximum, minimum, and mean temperature had the largest upward trend in autumn, while the biggest rise in potential evapotranspiration was in summer. This is because the precipitation in summer was larger than in autumn in the study area (Figure 2), and precipitation allows the identification of water availability for evapotranspiration [37].

\subsection{Implication of $M K$ and $M M K$ Tests}

The differences of trends in hydroclimatic variables indicate that an autocorrelation structure has great effects on trend analysis. Some results from the MK test may not be accurate, if the tested data series have significant serial correlation [38]. For instance, annual maximum temperature had no significant trend at the 5\% level when autocorrelation was considered. The MMK test may help to improve the results of trends [20]. Furthermore, precipitation seems to be the least correlated in time, because the changes of statistic $Z$ in precipitation at both stations were much lower than other variables when autocorrelation was considered. When excluding winter precipitation at Kyoto station from the analysis, the results of significant trends were not changed in all the precipitation statistics when autocorrelation was considered. Temperature and potential evapotranspiration were relative highly autocorrelated. The similarities in serial correlation support our finding that potential evapotranspiration was highly related with temperature. River discharge was also highly autocorrelated. This observation validates the earlier assumption that the decrease may be caused by human activities.

\subsection{Limitations}

The significant decrease in annual discharge is likely to pose a threat to the aquatic ecosystem and cultural amenities. It is necessary to evaluate the actual reasons for the decrease of river discharge in future study. In addition, the elevation of study area ranges from $17 \mathrm{~m}$ to $888 \mathrm{~m}$ and the average slope is $25.7^{\circ}$. The peak flow at the downstream will arrive quickly due to the terrain. The significant increase of annual precipitation at Kumogahata station located in a mountain area is likely to increase the flood risk. A future study on hourly extreme changes is necessary.

\section{Conclusions}

This study examined monotonic trends in annual and seasonal precipitation, temperature (in terms of maximum, minimum, and mean values), potential evapotranspiration, and river discharge from the hydrological year 1962 to 2017 in the Kamo River basin. Levene's test was used to evaluate the data homogeneity before trend analysis. The MK and MMK tests as well as Sen's slope estimator were used to analyze significant $(p<0.05)$ trends in time series with and without serial correlation and their magnitudes. The major findings include:

(1) We found a significant upward trend in annual, autumn, and winter precipitation at Kumogahata station, and no significant trend in precipitation at Kyoto station. Precipitation changes were less regular in different locations. In addition, precipitation trends were the least affected by the autocorrelation structure.

(2) Annual mean and minimum temperature and potential evapotranspiration notably increased. Also, the potential evapotranspiration and all the temperature variables significantly rose in summer.

(3) Annual river discharge significantly decreased by $0.09 \mathrm{~m}^{3} / \mathrm{s}$ after discarding the outliers. No significant trend was detected at the seasonal river discharge when the full autocorrelation structure was considered. 
(4) The hydroclimatic variables except precipitation were relatively highly autocorrelated, and serial correlation had great effects on trend analysis. The MK test may overestimate or underestimate the significance. The MMK test with full autocorrelation structure improved the accuracy of results of trends in this study.

To conclude, this study provides detailed information of trends in hydroclimatic variables in the Kamo River basin during recent decades, which is useful for decision makers to improve their planning and management of sustainable water resources.

Author Contributions: Conceptualization, M.H. and T.S.; Methodology, M.H.; Software, M.H.; Formal Analysis, M.H.; Data Curation, M.H. and S.T.; Writing-Original Draft Preparation, M.H.; Writing—Review \& Editing, M.H., T.S., S.T., K.T. (Kaoru Takara) and K.T. (Kenji Tanaka).

Funding: This research received no external funding.

Acknowledgments: This work was supported by the Kyoto University Global COE programme "Sustainability/Survivability Science for a Resilient Society Adaptable to Extreme Weather Conditions".

Conflicts of Interest: The authors declare no conflict of interest.

\section{References}

1. Donnelly, C.; Greuell, W.; Andersson, J.; Gerten, D.; Pisacane, G.; Roudier, P.; Ludwig, F. Impacts of climate change on European hydrology at 1.5, 2 and 3 degrees mean global warming above preindustrial level. Clim. Chang. 2017, 143, 13-26. [CrossRef]

2. Coumou, D.; Rahmstorf, S. A decade of weather extremes. Nat. Clim. Chang. 2012, 2, 491-496. [CrossRef]

3. Hu, M.; Sayama, T.; Zhang, X.; Tanaka, K.; Takara, K.; Yang, H. Evaluation of low impact development approach for mitigating flood inundation at a watershed scale in China. J. Environ. Manag. 2017, 193, 430-438. [CrossRef] [PubMed]

4. Hu, M.C.; Zhang, X.Q.; Li, Y.; Yang, H.; Tanaka, K. Flood mitigation performance of low impact development technologies under different storms for retrofitting an urbanized area. J. Clean. Prod. 2019, 222, 373-380. [CrossRef]

5. Hirabayashi, Y.; Kanae, S.; Emori, S.; Oki, T.; Kimoto, M. Global projections of changing risks of floods and droughts in a changing climate. Hydrol. Sci. J. 2008, 53, 754-772. [CrossRef]

6. Hirabayashi, Y.; Mahendran, R.; Koirala, S.; Konoshima, L.; Yamazaki, D.; Watanabe, S.; Kim, H.; Kanae, S. Global flood risk under climate change. Nat. Clim. Chang. 2013, 3, 816-821. [CrossRef]

7. Parr, D.; Wang, G. Hydrological changes in the U.S. Northeast using the Connecticut River Basin as a case study: Part 1. Modeling and analysis of the past. Glob. Planet. Chang. 2014, 122, 208-222. [CrossRef]

8. Luo, P.; Zhou, M.; Deng, H.; Lyu, J.; Cao, W.; Takara, K.; Nover, D.; Schladow, S.G. Impact of forest maintenance on water shortages: Hydrologic modeling and effects of climate change. Sci. Total Environ. 2018, 615, 1355-1363. [CrossRef] [PubMed]

9. Gedefaw, M.; Yan, D.; Wang, H.; Qin, T.; Wang, K. Analysis of the Recent Trends of Two Climate Parameters over Two Eco-Regions of Ethiopia. Water 2019, 11, 161. [CrossRef]

10. Partal, T.; Kahya, E. Trend analysis in Turkish precipitation data. Hydrol. Process. 2006, 20, $2011-2026$. [CrossRef]

11. Tian, J.; Liu, J.; Wang, J.; Li, C.; Nie, H.; Yu, F. Trend analysis of temperature and precipitation extremes in major grain producing area of China. Int. J. Climatol. 2017, 37, 672-687. [CrossRef]

12. Dorjsuren, B.; Yan, D.; Wang, H.; Chonokhuu, S.; Enkhbold, A.; Yiran, X.; Girma, A.; Gedefaw, M.; Abiyu, A. Observed Trends of Climate and River Discharge in Mongolia's Selenga Sub-Basin of the Lake Baikal Basin. Water 2018, 10, 1436. [CrossRef]

13. Chandniha, S.K.; Meshram, S.G.; Adamowski, J.F.; Meshram, C. Trend analysis of precipitation in Jharkhand State, India. Theor. Appl. Climatol. 2016, 130, 261-274. [CrossRef]

14. Capparelli, V.; Franzke, C.; Vecchio, A.; Freeman, M.P.; Watkins, N.W.; Carbone, V. A spatiotemporal analysis of U.S. station temperature trends over the last century. J. Geophys. Res. Atmos. 2013, 118, 7427-7434. [CrossRef]

15. Yue, S.; Hashino, M. Temperature trends in Japan: 1900-1996. Theor. Appl. Climatol. 2003, 75, 15-27. 
16. Parr, D.; Wang, G.; Ahmed, K.F. Hydrological changes in the U.S. Northeast using the Connecticut River Basin as a case study: Part 2. Projections of the future. Glob. Planet. Chang. 2015, 133, 167-175. [CrossRef]

17. Oguchi, S.; Fujibe, M. Seasonal and regional features of long-term precipitation changes in Japan. Pap. Meteorol. Geophys. 2012, 63, 21-30. [CrossRef]

18. Toride, K.; Cawthorne, D.L.; Ishida, K.; Kavvas, M.L.; Anderson, M.L. Long-term trend analysis on total and extreme precipitation over Shasta Dam watershed. Sci. Total Environ. 2018, 626, 244-254. [CrossRef]

19. Luo, P.; Kang, S.; Zhou, M.; Lyu, J.; Aisyah, S.; Binaya, M.; Regmi, R.K.; Nover, D. Water quality trend assessment in Jakarta: A rapidly growing Asian megacity. PLoS ONE 2019, 14, e0219009. [CrossRef]

20. Kumar, S.; Merwade, V.; Kam, J.; Thurner, K. Streamflow trends in Indiana: Effects of long term persistence, precipitation and subsurface drains. J. Hydrol. 2009, 374, 171-183. [CrossRef]

21. Duan, W.L.; He, B.; Takara, K.; Luo, P.P.; Hu, M.C.; Alias, N.E.; Nover, D. Changes of precipitation amounts and extremes over Japan between 1901 and 2012 and their connection to climate indices. Clim. Dyn. 2015, 45, 2273-2292. [CrossRef]

22. Peterson, T.C.; Easterling, D.R.; Karl, T.R.; Groisman, P.; Nicholls, N.; Plummer, N.; Torok, S.; Auer, I.; Boehm, R.; Gullett, D.; et al. Homogeneity adjustments of in situ atmospheric climate data: A review. Int. J. Climatol. 1998, 18, 1493-1517. [CrossRef]

23. Wijngaard, J.; Klein Tank, A.; Können, G. Homogeneity of 20th century European daily temperature and precipitation series. Int. J. Climatol. 2003, 23, 679-692. [CrossRef]

24. Brown, M.B.; Forsythe, A.B. Robust tests for the equality of variances. J. Am. Stat. Assoc. 1974, 69, 364-367. [CrossRef]

25. Allen, R.G.; Pereira, L.S.; Raes, D.; Smith, M. Crop evapotranspiration-Guidelines for computing crop water requirements-FAO Irrigation and drainage paper 56. FAO Rome 1998, 300, D05109.

26. Mann, H.B. Nonparametric tests against trend. Econom. J. Econom. Soc. 1945, 13, 245-259. [CrossRef]

27. Kendall, M.G. Rank Correlation Methods; Griffin: London, UK, 1975.

28. Latif, Y.; Yaoming, M.; Yaseen, M. Spatial analysis of precipitation time series over the Upper Indus Basin. Theor. Appl. Climatol. 2016, 131, 761-775. [CrossRef]

29. Hu, M.; Sayama, T.; Duan, W.; Takara, K.; He, B.; Luo, P. Assessment of hydrological extremes in the Kamo River Basin, Japan. Hydrol. Sci. J. 2017, 62, 1255-1265. [CrossRef]

30. Hamed, K.H.; Rao, A.R. A modified Mann-Kendall trend test for autocorrelated data. J. Hydrol. 1998, 204, 182-196. [CrossRef]

31. Sen, P.K. Estimates of the regression coefficient based on Kendall's tau. J. Am. Stat. Assoc. 1968, 63, 1379-1389. [CrossRef]

32. Fujibe, F. Relationship between Interannual Variations of Extreme Hourly Precipitation and Air/Sea-Surface Temperature in Japan. Sola 2015, 11, 5-9. [CrossRef]

33. Hirano, J.; Matsumoto, J. Secular and seasonal variations of winter monsoon weather patterns in Japan since the early 20th century. Int. J. Climatol. 2011, 31, 2330-2337. [CrossRef]

34. Nakamura, H.; Izumi, T.; Sampe, T. Interannual and decadal modulations recently observed in the Pacific storm track activity and East Asian winter monsoon. J. Clim. 2002, 15, 1855-1874. [CrossRef]

35. Hu, M.; Sayama, T.; Takahashi, S. impact assessment of human activities and climate change on annual runoff in the kamo river basin. Civ. Eng. Collect. Annu. J. Hydraul. Eng. JSCE 2016, 60, 451-456. [CrossRef]

36. Allamano, P.; Claps, P.; Laio, F.; Thea, C. A data-based assessment of the dependence of short-duration precipitation on elevation. Phys. Chem. Earth Parts A/B/C 2009, 34, 635-641. [CrossRef]

37. Beskow, S.; Norton, L.D.; Mello, C.R. Hydrological Prediction in a Tropical Watershed Dominated by Oxisols Using a Distributed Hydrological Model. Water Resour. Manag. 2012, 27, 341-363. [CrossRef]

38. Hamed, K.H. Trend detection in hydrologic data: The Mann-Kendall trend test under the scaling hypothesis. J. Hydrol. 2008, 349, 350-363. [CrossRef]

(C) 2019 by the authors. Licensee MDPI, Basel, Switzerland. This article is an open access article distributed under the terms and conditions of the Creative Commons Attribution (CC BY) license (http://creativecommons.org/licenses/by/4.0/). 